\title{
Colonic perforation with duodenal-colic fistula formation by a biliary stent in a liver transplant recipient
}

\author{
Christopher M. Moore ${ }^{1}$, Raza Hamdani ${ }^{2}$, Hector Ferral ${ }^{3}$, David H. Van Thiel ${ }^{1}$
}

\author{
${ }^{1}$ Section of Hepatology, Rush University Medical Center, Chicago, USA \\ ${ }^{2}$ Advanced Gastroenterology, Yorkville, USA \\ ${ }^{3}$ Section of Radiology, Rush University Medical Center, Chicago, USA \\ Email: David_vanthiel@rush.edu
}

Received 24 January 2012; revised 29 February 2012; accepted 1 March 2012

\begin{abstract}
Endoscopic retrograde cholangio-pancreatography (ERCP) is increasing utilized in the setting of liver transplantation for a number of post-operative related biliary issues. Although ERCP represents an excellent technology, it is not without attendant risk including sepsis, bleeding and perforation. In this case report, the first of its kind, is described the occurrence of a migrated biliary stent induced duodenal-colic fistula formation in a liver transplantation patient who had required dual biliary stenting given post-operative biliary structuring. The placement of dual stents and their size are likely implicated in the cause of perforation. The enteric anatomy and the medical immunosuppression likely contributed to a delay in diagnosis and worse outcome.
\end{abstract}

Keywords: Biliary Stent; Colonic Perforation; Duodenal-Colic Fistula; Hepatitis C Virus; Orthotopic Liver Transplant

\section{INTRODUCTION}

Liver transplantation represents a definitive treatment for many forms of chronic liver disease, and with increasing utilization has brought with it the attendant risks such as post-operative biliary structuring or occlusion. As such Endoscopic retrograde cholangiopancreatography (ERCP) has also been increasing utilized in this group of patients for both diagnostic and therapeutic purposes. While undoubtedly an excellent technology, ERCP carries particular risks, in the setting of biliary stenting, these include complications of pancreatitis $(\sim 5 \%)$, cholangitis $(<5 \%)$ and perforation $(<1 \%)$ [1-3]. Herein, is reported a novel case of biliary stent perforation with duodenal-colic fistula formation in an orthotopic liver transplant (OLT) patient.

\section{CASE REPORT}

A 50 year-old male with chronic Hepatitis C Virus (HCV) infection and hepatocellular carcinoma (HCC) underwent orthotopic liver transplant (OLT) in 2009. Post-operatively, he remained in good health until 3 months prior to admission to our institution when he was found to have a biliary anastomotic stricture which was managed successfully with ERCP placement of two adjacent biliary stents. However, two months later he developed similar obstructive biliary signs (Table 1). An ERCP noted two biliary stents extending through the papilla which were removed. The common bile duct appeared strictured and thus a 10 French $(F) \times 12 \mathrm{~cm}$ stent was extended beyond it. A second stent, measuring $7 \mathrm{~F} \times 12 \mathrm{~cm}$ was placed in

Table 1. Hematologic parameters of the patient through key portions of his hospitalization $(\mathrm{TB}=$ total bilirubin; $\mathrm{DB}=$ direct bilirubin; AP = alkaline phosphatase; AST = aspartate aminotransferase; ALT = alanine aminotransferase).

\begin{tabular}{lcccccccc}
\hline & $\begin{array}{c}\mathrm{TB} \\
(\mathrm{mg} / \mathrm{dL})\end{array}$ & $\begin{array}{c}\mathrm{DB} \\
(\mathrm{mg} / \mathrm{dL})\end{array}$ & $\begin{array}{c}\text { Albumin } \\
(\mathrm{g} / \mathrm{dL})\end{array}$ & $\begin{array}{c}\text { AP } \\
(\mathrm{U} / \mathrm{L})\end{array}$ & $\begin{array}{c}\text { AST } \\
(\mathrm{U} / \mathrm{L})\end{array}$ & $\begin{array}{c}\text { ALT } \\
(\mathrm{U} / \mathrm{L})\end{array}$ & $\begin{array}{c}\text { WBC } \\
\left(10^{3} / \mu \mathrm{l}\right)\end{array}$ & $\begin{array}{c}\text { INR } \\
(\mathrm{unitless})\end{array}$ \\
\hline Pre-ERCP \#2 (before stents re-placed). & 3.6 & N/A & 2.5 & 959 & 72 & 57 & 6.6 & N/A \\
Day 1: Admission (3 weeks after ERCP \#2). & 5.7 & N/A & 2.2 & 1127 & 89 & 62 & 3.8 & 1.09 \\
Day 2: Post-surgical removal of stent \#1. & 4.4 & 3.7 & 1.4 & 521 & 61 & 33 & 6.3 & 1.08 \\
Day 7: Post-ERCP \#3, with endoscopic removal of stent \#2. & 6.0 & 4.9 & 1.9 & 803 & 143 & 75 & 4.7 & 1.14 \\
Day 14: $~ 1$ week post-ERCP \#3. & 7.0 & 6.0 & 1.6 & 391 & 39 & 36 & 3.6 & 1.26 \\
Day 20: 2 week post-ERCP \#3, death. & 14.7 & 11.4 & 1.9 & 512 & 62 & 27 & 6.9 & 1.98 \\
\hline
\end{tabular}


parallel to the first, approximately $2 \mathrm{~cm}$ beyond the larger stent, into the right hepatic ductal system. There was appropriate biliary drainage thereafter. He displayed overall improvement, yet 3 weeks later he again decompensated (see Table 1) and was transferred to our institution for further evaluation. A computed tomography (CT) scan on admission revealed that one of the biliary stents had penetrated through the duodenum and into the ascending colon (Figure 1). The patient was started on broad-spectrum antibiotics and underwent an exploratory laparotomy, wherein it was observed that one of the biliary stents had indeed formed a duodenal-colic fistula. This stent was removed and the colonic and duodenal walls were individually closed with sutures. A diverting ileostomy was performed as well. A few days later, an ERCP was performed and the second stent (protruding though the papilla) was removed; visualization of the biliary system displayed no new abnormalities. Some improvement in his clinical status was observed initially (Table 1).

Nevertheless, the patient's clinical status deteriorated, developing sepsis with multi-organ failure and resultant death (see Table 1). No abscess or fluid collection was identified with CT imaging post-operatively and prior to his death.

\section{DISCUSSION}

Duodenal perforation by a biliary stent has been reported previously [3,4]. No prior reports of a duodenal-colonic fistula by a biliary stent have been reported. Biliary stent

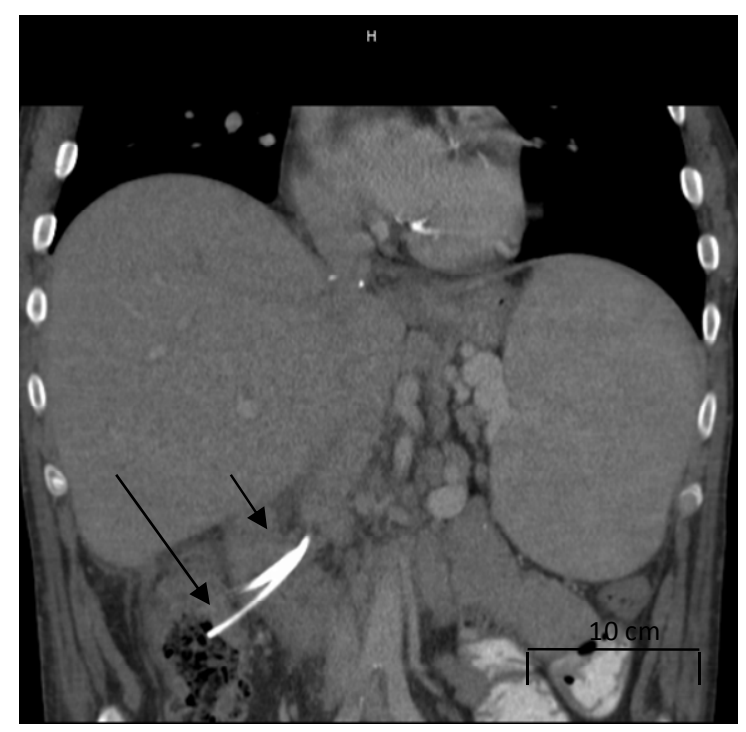

Figure 1. Coronal imaging of the CT of the abdomen displaying two adjacent biliary stents, with one penetrating through the duodenum into the ascending colon (long arrow), creating a duodenal-colic fistula; and, the second stent still remaining in position and protruding into the duodenum (short arrow). associated perforations have been reported equally with all types of stents regardless of their material, shape or diameter. Nonetheless, factors such as improper technique, or placement, and the caliber or length of the stent extending into the duodenum may play a role in at least some of these cases [4,5]. Additionally, atypical enteric geometry may predispose to such complications in the setting of hernias, malrotations and diverticular disease. In the present case, it is believed that the unusual length of the stents into the duodenum and the placement of two stents (with the larger one protruding $2 \mathrm{~cm}$ further into the duodenum, and the smaller one providing both rigidity and directional force) may have enabled the offending stent to penetrate through the lateral duodenal wall and into the ascending colon.

The clinical presentation of a biliary stent-associated perforation can include non-specific abdominal pain, nausea, vomiting and fevers [4]. In this case, the epigastric location, the lack of peritonitis, and the patient's immunosuppression contributed to a delayed diagnosis and institution of therapy.

In summary, this case is notable as it is the first to involve 1) the formation of duodenal-colic fistula; and, 2) occurring as a result of two adjacent biliary stents being placed at unequal distances into the biliary tree. Although this case report represents a rare event, unusual manifestations of perforation in a liver transplant patient must be entertained given the ever increasing utilization of such endoscopic procedures. It is hoped that awareness especially given specific patient risk factors, will lead to a more rapid diagnosis and hence treatment to prevent such adverse outcomes as described here.

\section{REFERENCES}

[1] ASGE Guideline (2005) The role of ERCP in diseases of the biliary tract and the pancreas. Gastrointestinal Endoscopy, 62, 1-8. doi:10.1016/j.gie.2005.04.015

[2] Freeman, M.L. (2003) Understanding risk factors and avoiding complications with endoscopic retrograde cholangiopancreatography. Current Gastroenterology Reports, 5, 145-153. doi:10.1007/s11894-003-0084-9.

[3] Saranga Bharathi, R., Rao, P. and Ghosh, K. (2006) Iatrogenic duodenal perforations caused by endoscopic biliary stenting and stent migration: An update. Endoscopy, 38, 1271-1274. doi:10.1055/s-2006-944960

[4] Melita, G., Currò, G., Iapichino, G., Princiotta, S. and Cucinotta, E. (2005) Duodenal perforation secondary to biliary stent dislocation: A case report and review of the literature. Chirurgia Italiana, 57, 385-388.

[5] Elliott, M. and Boland, S. (2003) Sigmoid colon perforation following a migrated biliary stent. ANZ Journal of Surgery, 73, 669-670. doi:10.1046/j.1445-2197.2003.02698.x 